\title{
Editorial
}

\section{Continuous Subcutaneous Insulin Infusion: A Developing Tool in Diabetes Research}

\author{
J. C. Pickup and H. Keen \\ Guy's Hospital Medical School, London, England
}

The 1970s have been an important decade in the history of diabetes research; the mysteries of causation have started to unravel, the goal of achieving metabolic near-normalisation in diabetics seemed at last to have been caught within the sights of physicians, surgeons, bioengineers and medical scientists alike, all anxious to develop better ways of administering insulin to patients.

There are four related reasons why these efforts have taken place. 1) An hypothesis. The debate on whether strict control of diabetes can slow, prevent or reverse the complications has continued for decades [1]. Only recently, however, has substantial and cogent evidence accumulated that microvascular changes occurring in animals with experimental diabetes regress if the metabolic disorder of the disease is returned toward normal [2]. 2) A need. This link has not been conclusively established in human diabetics because of the difficulty of maintaining prolonged near-normoglycaemia with traditional insulin injection treatment. The advent of continuous blood glucose monitoring $[3,27]$ and frequent sampling profiles have pointed quite clearly to the deficiencies in currently available therapy, and the need for new pharmacological approaches to diabetic control. 3) An expectation. Putting a man on the moon was no mean technological feat. It was not unreasonable to hope for similar medical tours de force [4], drawing on the new skills in bioengineering, computers and electronic miniaturisation. 4) $A$ determination. The awesome fact that morbidity and mortality as a direct consequence of diabetic complications continues unabated perhaps was the drive behind the concerted attack on the problem released once the means seemed to be available, even though the aetiology was, and is, so ill-defined.

A central tenet is the idea that better physiological responses could result from insulin replacement administered in a more physiological way than bolus subcutaneous injections. In simple terms the B-cell delivers insulin into the blood stream at two rates: a continuous, slow basal rate, which controls glucose output from the liver and restrains lipolysis and proteolysis and meal-time bursts which dispose of the digested nutrients. Furthermore, because glucose is a stimulus for insulin release, a servo-control maintains blood glucose levels within narrow limits at all times of the day. Various mechanical devices for blood glucose control have been designed toward recreating these physiological characteristics.

The "artificial pancreas" is a closed-loop system, i. e. an extra-corporeal blood glucose sensor is coupled to a computer which calculates and regulates the rate of infusion of insulin into a peripheral vein necessary to maintain normoglycaemia [5]. At present, the scope of this apparatus is limited by its bulk, complexity and cost and its use of the intravenous route for insulin administration and for blood sampling. The unit is too large for portable use in ambulatory patients and prolonged infusions carry the risk of thrombosis and infection.

Beginning with the work of Slama et al. in 1974 [6], many reports now indicate that almost as good blood glucose concentrations can be achieved using much simpler portable infusion pumps without glucose-sensing and feedback control (i. e. "open-loop" devices) [7-12]. The meal-time augmented delivery can be pre-programmed or selected by the patient. Some devices employ complicated modelling of the prandial infusion rate wave-form so as to closely match the pattern of insulin secretion of the nondiabetic but good results are also obtained with just one or two high levels. Most systems infuse insulin into a peripheral vein and although studies of up to 3 months are described in a very few patients [11] vascular problems could again restrict safe applica- 
tion. As long ago as 1934, Metcalfe [13] suggested that diabetics might be treated by continuous subcutaneous insulin infusion (CSII). Our rediscovery and exploration of the technique had a rather different and more specific goal: to develop a means to restore the metabolic abnormalities of diabetes to near-normal for long enough to test in man the hypothesis that microangiopathy is slowed, stopped or reversed by strict diabetic control $[14,15]$. It takes the advantages of the open-loop approach, outlined above, combined with the variable delivery of very small volumes of insulin subcutaneously, a route designed to prevent problems at the insulin/body interface during extended treatment, and uses a portable system compatible with normal life.

Pilot studies [14, 15] employed a specially adapted, portable, electromechanical syringe pump (the Mill Hill Infuser [16]) weighing about $300 \mathrm{~g}$ and capable of delivering insulin at two fixed rates: $50 \mu \mathrm{l} /$ $\mathrm{h}$ or $400 \mu \mathrm{l} / \mathrm{h}$. The high rate was electronically engaged by the patient 30 minutes before each main meal (to allow for absorption of insulin) and automatically returned to the basal level after a preset time. A number of pumps have since been tried for subcutaneous insulin infusions including those of Pye Dynamics Ltd. [17] and Autosyringe Inc. [18-20]. Both have more flexible rate adjustments, not necessarily desirable for safe, simple outpatient use. Moreover, recent pharmacokinetic studies [21] indicate that there is little difference between the absorption pattern of a bolus of insulin injected subcutaneously and the same dose and volume infused subcutaneously over the preset time. An infuser with facility for manual injecton of bolus quanta at mealtimes (Muirhead Ltd. Beckenham, Kent) would thus be equally suitable and totally adaptable to individual requirements.

In our own studies insulin is delivered through a fine nylon cannula so as to minimise discharge of insulin by random flexing of the cannula and to present the smallest surface for irritation and foreign body reaction. The distal $3 \mathrm{~cm}$ or so are implanted in the subcutaneous tissue of the abdominal wall, using local anaesthetic and an introducing needle [15]. Others have had good (short-term) results using finegauge metal needles attached permanently to the plastic infusion cannulae and re-inserted every day or so $[18,19]$. Prolonged infusion at the same site might be expected to lead to local tissue reaction at the free end of the cannula but in patients treated by CSII for 2-4 months no lipodystrophy, infection or other adverse tissue reaction has been noted even when a single cannula was used at the same site for 2 months.

There are now several reports which show that near physiological blood glucose concentrations can be continuously maintained by CSII for a number of days in ambulatory insulin-dependent diabetics supervised in hospital $[14,15,17-20,22,24,25]$. Thus, we found that the mean plasma glucose on the final infusion day in five patients treated for up to 4 days [24] ranged from 5.5 to $8.2 \mathrm{mmol} / \mathrm{l}$, while Tamborlane et al. [19] report final mean daily plasma glucose values of between 4.2 and $5.2 \mathrm{mmol} / 1$ in 6 patients infused for 14 days. Hypoglycaemia presents unexpectedly few problems and this point is confirmed by a decrease in the M-value, an index of blood glucose variability [26, 27], after CSII.

Experience with long-term outpatient subcutaneous insulin infusion is only just emerging. A trial group of six diabetics treated at home by CSII for 2-4 months achieved overall mean blood glucose values ranging from 4.8 to $7.5 \mathrm{mmol} / 1[23,28]$. Patients monitored their own capillary blood glucose levels with glucose oxidase strips (Dextrostix ${ }^{\mathbb{E}}$ ) and changed the insulin in the pump daily. A Canadian group have also reported preliminary but encouraging studies in diabetics at home [25]. During these infusions mean fasting free plasma insulin levels have been about $10-15 \mathrm{mU} / 1$ with post-prandial peaks of $30-50 \mathrm{mU} / 1$ about 75 minutes after switching to the high rate $[21,25,44]$.

Glucose is easily and, therefore, frequently measured in blood and urine, but its role in the pathogenesis of microangiopathy has yet to be determined. Many intermediary metabolites and hormones are abnormal in concentration in diabetes, at least in relation to accompanying blood glucose concentrations [29-31]. It is possible that other metabolites, such as lactate [32-36], contribute to, or are even responsible, for the pathological processes. If the definition of diabetic control is widened to include these, improved control must include demonstrable normalisation of at least some of these other variables. Treatment of diabetics by CSII $[19,37]$ is associated with return to near-normal of blood levels of lactate, pyruvate, 3-hydroxybutyrate, alanine, cholesterol, triglyceride, free fatty acids and branched chain amino acids. Similarly, normalisation of growth hormone and catecholamine response to exercise has been reported [45].

How close to normal must we aim to get to show an effect on microvascular disease (or, realistically, to meet the challenge that we had not done well enough if we fail)? Epidemiological studies $[39,40]$ may give some pointers. They indicate there may be a 'glycaemic threshold' below which retinopathy and nephropathy are unlikely to occur. The critical indicator level appears to be a value of about $11 \mathrm{mmol} / 1$ two hours after an oral glucose load. Of course, few people with the lesser degrees of glucose intolerance ever 
approach these values of glycaemia during the course of a normal day. In blood glucose concentrations measured randomly after normal meals during the afternoon in the Bedford borderline subjects only about $2 \%$ of values exceeded $140 \mathrm{mg} / \mathrm{dl}(7.8 \mathrm{mmol} /$ 1). Our experience with a group of highly motivated well instructed self-monitoring and self-correcting diabetics on CSII suggests that a top value of $8 \mathrm{mmol} / 1$ is attainable $[23,28]$.

The power of even short periods of "super control" has been recently demonstrated in a group of long-standing diabetics without clinical proteinuria but with a demonstrated increase in urinary albumin excretion during conventional treatment, measured by sensitive radio-immunoassay [41]. After only 1-3 days on CSII protein excretion was reduced in all and, in some, actually normalised. The failure of $\beta_{2}$ microglobulin excretion to alter during infusion suggests a change in glomerular capillary permeability rather than tubular function. An important aspect of these results is the demonstration that renal glomerular microvascular function can be improved, even in these long-standing diabetics, so fast as to preclude structural changes in, for example, the basement membrane thickness. Perhaps clinical nephropathy can be delayed by longer-term CSII-induced strict control. Encouraging results have also been obtained in two patients with florid proliferative or pre-proliferative retinopathy who were infused subcutaneously for 3-4 months [42]. Serial fluorescein angiograms demonstrated arrest of retinopathy in one patient and marked regression in the other.

Two other areas in which CSII might have direct therapeutic value are in diabetic pregnancy where preliminary studies have been reported [17], and in the induction of remissions in newly-diagnosed insulin-requiring diabetics. Mirouze et al. recently used an artificial pancreas to achieve a few days of initial normoglycaemia in newly-diagnosed diabetics and was able to induce a greatly increased percentage of "honeymoon" type remissions [43]. Strict control may preserve or improve endogenous pancreatic function by sustained relief of $\mathrm{B}$ cells from overstimulation. The longer periods of such relief possible with CSII has already been explored with encouraging results in two newly diagnosed diabetics but more work is needed in this area.

One type of diabetic that desperately needs improved control is the truly brittle patient. If one takes the definition of brittle diabetes as a relatively rare syndrome of large, fast and unpredictable swings in blood glucose that seem unrelated to insulin administration, food or exercise then CSII has not helped - at least in one case we recently studied [24]. There are, undoubtedly, though, some "unstable" diabetics who present with multiple episodes of ketosis and who can be improved by the flexible, more efficient and physiological approach of CSII. Clearly, there is much to be learned about the nature and causes of these problem cases in diabetic management.

The more obvious warning about CSII is the realisation that patients treated by open-loop systems have little or no insulin reserve, exogenous or endogenous. We have observed rapidly rising blood glucose levels and ketosis after accidental cannula withdrawal. During severe stress and intercurrent illness, insulin requirements increase and may demand injection of extra insulin by conventional means in order to maintain control. CSII should, therefore, be operated only under the strictest supervision of medical staff and with constant self-monitoring by the patients. Motivation must be high and instruction adequately given and demonstrably received to cover the problems and even the emergencies that may arise. Many of the early problems inherent in any new technique have been identified and overcome but, in our view, CSII remains an experimental procedure which is still far from being a safe treatment routine.

New forms of insulin delivery offer several prospects for the future. Not only are they of therapeutic value in themselves but may also indicate the intensity of effort and level of control which must be sought henceforth with conventional therapy. It is also our hope that impetus will be given thereby to evolving other even more effective pharmacological techniques.

\section{References}

1. Tchobroutsky $G$ (1978) Relation of diabetic control to development of microvascular complications. Diabetologia 15: $143-152$

2. Engerman R, Bloodworth JMB, Nelson S (1977) Relationship of microvascular disease to metabolic control. Diabetes 26: $760-769$

3. Molnar GD, Taylor WF, Ho MM (1972) Day-to-day variation of continuously monitored glycaemia: a further measure of diabetic instability. Diabetologia 8: 342-348

4. Arky RA (1979) The engineering of blood sugar. N Engl J Med 300: 618-619

5. Albisser AM, Leibel BS (1977) The artificial pancreas. Clin Endocrinol Metab 6: 437-447

6. Slama G, Hautcouverture M, Assan R, Tchobroutsky G (1974) One to five days of continuous insulin infusion on seven diabetic patients. Diabetes 23: 732-738

7. Deckert T, Lørup B (1976) Regulation of brittle diabetes by a preplanned infusion programme. Diabetologia 12: 573-579

8. Hepp KD, Renner R, Funcke HJ, Mehnert H, Haerten R, Kresse H (1977) Glucose homeostasis under continuous intravenous insulin therapy in diabetics. Horm Metab Res [Suppl] 7: 72-76 
9. Genuth S, Martin P (1977) Control of hyperglycaemia in adult diabetics by pulsed insulin delivery. Diabetes 26: 571-581

10. Service F J (1978) Normalization of plasma glucose of unstable diabetes: studies under ambulatory, fed conditions with pumped intravenous insulin. J Lab Clin Med 91: 480-489

11. Irsigler K, Kritz H (1979) Long-term continuous intravenous insulin therapy with a portable insulin dosage-regulating apparatus. Diabetes 28: 196-203

12. Hanna AK, Minuk HL, Zinman B, Marliss EB, Ellman J, Leibel BS, Albisser AM (1978) A portable system for continuous intravenous insulin delivery: characteristics and results in human diabetics. Clin Res 26: 630 A

13. Metcalf J (1934) The administration of insulin by continuous injection. M. B. Thesis, University of Cambridge

14. Pickup J C, Keen H, Parsons J A, Alberti K GMM (1977) The use of continuous subcutaneous insulin infusion to achieve normoglycaemia in diabetic patients. Diabetologia 13: 425 A

15. Pickup JC, Keen H, Parsons J A, Alberti KGMM (1978) Continuous subcutaneous insulin infusion: an approach to achieving normoglycaemia. Br Med J I: 204-207

16. Parsons J A, Rothwell D, Sharpe JE (1977) A miniature syringe pump for continuous administration of drugs and hormones: the Mill Hill Infuser. Lancet I: 77-78

17. Potter JM, Reckless JPD, Cullen D R (1978) The control of glucose and intermediary metabolites in pregnant diabetic patients on different insulin regimens. Clin Sci Mol Med 55: 4

18. Tamborlane WV, Sherwin RS, Genel M, Felig P (1979) Reduction to normal of plasma glucose in juvenile diabetes by subcutaneous administration of insulin with a portable infusion pump. N Engl J Med 300: 573-578

19. Tamborlane WV, Sherwin RS, Genel M, Felig P (1979) Restoration of normal lipid and amino acid metabolism in diabetic patients with a portable insulin-infusion pump. Lancet I: $1258-1261$

20. Riley WJ, Silverstein JH, Rosenbloom AL (1979) Ambulatory diabetes management by a pulse of subcutaneous insulin delivered by a portable pump: preliminary report. Diabetes Care 2: 272-274

21. Home P, Pickup J C, Keen H: Unpublished data

22. Pickup JC, Keen H, Stevenson RW, Parsons J A, Alberti K GMM, White M, Kohner EM (1978) Insulin via continuous subcutaneous infusion. Lancet II: 988-989

23. Pickup JC, White MC, Keen H, Kohner EM, Parsons JA, Aberti, K GMM (1979) Long-term continuous subcutaneous insulin infusion in diabetics at home. Lancet II: 870-873

24. Pickup JC, Keen H, Parsons J A, Alberti KGMM (1979) Continuous subcutaneous insulin infusion: good blood glucose control for up to 4 days. Diabetologia 16: 385-389

25. Champion M, Shepherd G, Rodger HW, Dupré J (1979) Continuous subcutaneous insulin infusion in treatment of diabetes mellitus. Diabetes 28: 383

26. Schlichtkrull J, Munck O, Jersild M (1965) The M-value, an index of blood sugar control in diabetics. Acta Med Scand 177: 95-102

27. Service FJ, Molnar GD, Rosevear JW, Ackerman E, Gatewood LC, Taylor WF (1970) Mean amplitude of glycaemic excursions, a measure of diabetic instability. Diabetes 19: 644-655

28. Pickup J C, Keen H, White MC, Kohner EM, Parsons J A (In press) Long-term continuous subcutaneous insulin infusion in outpatient diabetics. Proceedings of the Workshop on the Artificial Beta Cell, Heviz, Hungary

29. Alberti KGMM, Dornhorst A, Rowe AS (1975) Metabolic rhythms in normal and diabetic man. Studies in insulin-treated diabetes. Isr J Med Sci 11: 571-580

30. Unger RH, Orci L (1977) Role of glucagon in diabetes. Arch Intern Med 137: 482-491

31. Lundbaek K, Christensen N J, Jensen V A, Johansen K, SteenOlsen T, Prange Hansen A, Ørskov H, Østerby R (1970) Diabetes, diabetic angiopathy and growth hormone. Lancet II: 131-133

32. Ashton N (1957) Retinal neovascularization in health and disease. Am J Ophthalmol 44: 7-17

33. Wise GN (1961) Factors influencing new vessel formation. Am J Ophthalmol 52: 637-650

34. Henkind P, Wise GN (1974) Retinal neovascularization, collaterals and vascular shunts. Br J Ophthalmol 58: 413-422

35. Imre G (1977) The role of lactic acid in neovascularization. Albrecht von Graefes Arch Klin Ophthalmol 201: 263-266

36. Gerke E, Spitznas M, Brodde O-E (1976) The role of lactic acid in retinal neovascularization. Albrecht von Graefes Arch Klin Ophthalmol 200: 79-84

37. Pickup J C, Keen H, Parsons J A, Alberti K GMM, Rowe AS (1979) Continuous subcutaneous insulin infusion: improved blood glucose and intermediary metabolite control in diabetics. Lancet I: $1255-1258$

38. Jarrett RJ, Keen H (1976) Hyperglycaemia and diabetes mellitus. Lancet II: 1009-1012

39. Dorf A, Ballintine EJ, Bennett PH, Miller M (1976) Retinopathy in Pima Indians. Diabetes 25: 554-560

40. Rushforth N B, Miller M, Bennett PH (1979) Fasting and twohour post-load glucose levels for the diagnosis of diabetes. Diabetologia 16: 373-379

41. Viberti GC, Pickup J C, Jarrett R J, Keen H (1979) Effect of control of blood glucose on urinary excretion of albumin and $\beta_{2}$ microglobulin in insulin-dependent diabetes. $\mathrm{N}$ Engl $\mathrm{J}$ Med 300: 638-641

42. White MC, Kohner EM, Pickup J C, Keen H: Improvement in retinal vascular changes on continuous subcutaneous insulin infusion (CSII). Presented at British Diabetic Association Meeting, September 1979

43. Mirouze J, Selam J L, Pham TC, Mendoza E, Orsetti A (1978) Sustained insulin-induced remissions of juvenile diabetes by means of an external artificial pancreas. Diabetologia 14: 223-227

44. Slama G, Buu KNP, Tchobroutsky G, Delage A, Desplanque N (1979) Plasma insulin and C-peptide levels during continuous subcutaneous insulin infusions. Diabetes Care 2: 251-255

45. Tamborlane WV, Sherwin RS, Koivisto V, Hendler R, Genel M, Felig P (1979) Normalization of the growth hormone and catecholamine response to exercise in juvenile-onset diabetic subjects treated with a portable insulin infusion pump. Diabetes 28: 785-788

Dr. J. C. Pickup

Unit for Metabolic Medicine

Guy's Hospital Medical School

London SE1 9RT

England 